\title{
HÉMERY-HERVAIS SIMA EYI, Sociocritique du roman gabonais. De la méthode à l'analyse du texte
}

\section{Elena Fermi}

\section{OpenEdition}

\section{Journals}

\section{Édition électronique}

URL : https://journals.openedition.org/studifrancesi/12243

DOI : $10.4000 /$ studifrancesi. 12243

ISSN : 2427-5856

\section{Éditeur}

Rosenberg \& Sellier

\section{Édition imprimée}

Date de publication : 1 avril 2018

Pagination : 176-177

ISSN : 0039-2944

\section{Référence électronique}

Elena Fermi, « HÉMERY-HeRvaIS SIMA EYI, Sociocritique du roman gabonais. De la méthode à l'analyse du texte », Studi Francesi [En ligne], 184 (LXII | I) | 2018, mis en ligne le 04 juillet 2018, consulté le 17 novembre 2021. URL : http://journals.openedition.org/studifrancesi/12243 ; DOI : https://doi.org/ 10.4000/studifrancesi. 12243

Ce document a été généré automatiquement le 17 novembre 2021.

\section{(c) (i) (9) $\Theta$}

Studi Francesi è distribuita con Licenza Creative Commons Attribuzione - Non commerciale - Non opere derivate 4.0 Internazionale. 


\title{
HÉMERY-HERVAIS SIMA EYI, Sociocritique du roman gabonais. De la méthode à l'analyse du texte
}

\author{
Elena Fermi
}

\section{RÉFÉRENCE}

HÉMERY-HERVAIS SIMA EYI, Sociocritique du roman gabonais. De la méthode à l'analyse du texte, Paris, L'Harmattan, 2016, 288 pp.

1 Le présent ouvrage est issu d'une thèse de doctorat soutenue par l'auteur en 1997 à l'Université Laval de Québec, après des années d'étude et de travail qui l'ont amené à recueillir un corpus important de romans gabonais contemporains et à les analyser à la lumière des théories sociocritiques de Claude Duchet. SIMA EYI fait rencontrer dans ce volume une approche théorique développée dans le vieux monde et un objet nouveau et hautement problématique tel que le roman gabonais de la période 1983 à 1992. Il innove cette approche à travers sa réflexion personnelle, en devenant le pionnier d'un champ de recherche nouveau. Après une introduction dans laquelle l'auteur fait le point sur la situation linguistique et littéraire francophone en Afrique subsaharienne et, en particulier, au Gabon, l'ouvrage se développe sur quatre grands chapitres.

Le premier, qui est également le plus long, met l'accent sur le cadre théorique et méthodologique dans lequel l'auteur va inscrire son analyse. Il entend distinguer la sociocritique des sociologies de la littérature et de celles des institutions littéraires pour la définir comme une sociologie du texte, dont l'objet va donc être uniquement le texte, notamment la question du social dans le texte littéraire. À partir des théories élaborées par Claude Duchet - qui reste sa référence principale - l'auteur va centrer son attention sur la question de l'oralité, élément typique du roman subsaharien francophone en général et gabonais en particulier et qui est, en revanche, absent des littératures du vieux continent à partir desquelles Duchet a élaboré sa méthode. 
L'analyse de l'oralité - nouvelle marque du social dans le texte littéraire - introduit un élément nouveau dans la sociocritique. La question de la mise en texte des discours sociaux est aussi affrontée, en ayant recours, encore une fois, aux études de Claude Duchet et à celles de Régine Robin. L'auteur dit vouloir aborder son analyse à partir de la société historique préexistant au texte et de la société de référence, pour advenir à la société du roman, dont les deux premières sont le prélude. Il définit également son corpus, constitué par six œuvres romanesques: G'arnàrakano d'Angèle NtyugwétondoRawiri, Fureurs et cris de femmes d'Angèle Rawiri, La mouche et la glu de Maurice Okoumba-Nkoghé, Biboubouah: chroniques équatoriales de Ferdinand Allogho-Oke, Au bout du silence de Laurent Owondo et Les matitis de Hubert Freddy Ndong Mbeng.

3 Le deuxième chapitre aborde la question de la représentation de la femme et du combat féministe à travers les deux espaces sociotextuels représentés dans la société du roman, le village et la ville. L'auteur tente de saisir l'évolution du personnage féminin et sa capacité d'expression dans ces deux espaces sociaux, le premier caractérisé par le poids de lois traditionnelles qui ne donnent à la femme aucun rôle social, le deuxième marqué par plus de dynamisme mais aussi par une division beaucoup plus tragique entre riches et pauvres, scolarisés et illettrés, européens et africains. Si, dans l'espace villageois, la femme se caractérise par une remise en cause des lois traditionnelles qu'elle va jusqu'à défier, dans l'espace urbain elle est au centre de la question de l'émancipation qui reste cependant un phénomène lié à certains milieux, à certaines classes sociales et à certaines générations et qui est rendu faible à cause de la division des femmes qui mènent des combats différents, suivant le groupe, la classe sociale et la génération d'appartenance. La question de la scolarisation féminine, donc du rôle joué par l'école dans la macrostructure de l'État et auprès des citoyens, est également abordée, afin de traiter la participation des femmes à l'action politique. À travers le corpus de romans analysés par Sima Eyi, on assiste à des approches différentes de la problématique féminine qui arrive, dans Fureurs et cris de femmes, à présenter le personnage féminin comme acteur social au même titre que l'homme.

4 Le troisième chapitre met l'accent sur le rapport entre le texte narratif et les idéologies institutionnelles que le texte littéraire met en fiction et élargit donc la question à la représentation de la société gabonaise dans le roman. Le rôle de l'école y est abordé tout comme celui de la religion et de la politique, afin de souligner la relation entre la société de roman, la société de référence et la société historique. Le roman gabonais, à travers le discours sociotextuel, révèle son caractère dénonciateur des injustices sociales et assume une portée idéologique, en soulignant la complicité du système politique au maintien d'une situation d'inégalité et de déséquilibre social.

Dans le dernier chapitre, l'auteur aborde la question de l'oralité et de la crise de la parole dans le roman gabonais. La présence d'un narrateur-conteur marque, dans certains romans du corpus, la différence par rapport au roman occidental de type balzacien. On y retrouve des marques de la tradition à travers la place faite au carnavalesque, au grotesque et à l'ironie qui évoquent le Mvett, genre littéraire oral et épopée traditionnelle. Le narrateur y apparaît comme la résurgence de l'oralité et rappelle l'importance du conteur dans la société traditionnelle. La cohabitation de la langue française avec la langue du terroir confirme ultérieurement ce souci de représentation fidèle de la société de référence dans la société du roman. Il reste cependant le problème de rendre le discours oral à travers l'écriture. Les romanciers font généralement le choix de transcrire les discours oraux en utilisant l'alphabet français 
ce qui, d'un côté, favorise la lisibilité et la diffusion de leurs ouvrages mais, de l'autre, met de plus en plus en crise les langues du terroir. Le silence, enfin, joue lui aussi un rôle fondamental dans le roman gabonais où il se configure comme le lieu du non-dit et de l'implicite.

6 L'approche sociocritique du roman permet, selon Sima Eyi, de se rendre compte du fait que l'évocation d'un fait social est la conséquence de faits antérieurs que le roman n'intègre pas et ne représente pas de manière explicite et ouvre, selon lui, d'autres problématiques telles que celle du phénomène discursif et de son rapport avec la philosophie culturelle de la société représentée et celle du rapport que développe le roman avec les langages des milieux qu'il représente.

7 Le volume présente en annexe des représentations figuratives de la société gabonaise à travers les espaces sociotextuels, et plusieurs tables synoptiques qui permettent au lecteur de se repérer du point de vue historique et culturel. La bibliographie qui clôt l'ouvrage présente des références importantes pour tout approfondissement ultérieur. 